\title{
A qualitative study of perspectives on household and societal impacts of demand response
}

\section{Niamh Murtagh, Birgitta Gatersleben \& David Uzzell}

To cite this article: Niamh Murtagh, Birgitta Gatersleben \& David Uzzell (2014) A qualitative study of perspectives on household and societal impacts of demand response, Technology Analysis \& Strategic Management, 26:10, 1131-1143, DOI: 10.1080/09537325.2014.974529

To link to this article: http://dx.doi.org/10.1080/09537325.2014.974529

\section{(c) 2014 The Author(s). Published by Taylor \& Francis}

\section{Published online: 05 Nov 2014.}

Submit your article to this journal 주
Џ Article views: 819

Q View related articles $\sqsubset$

View Crossmark data \lceil

4

Citing articles: 4 View citing articles $₫$ 


\title{
A qualitative study of perspectives on household and societal impacts of demand response
}

\author{
Niamh Murtagh ${ }^{\mathrm{a}, \mathrm{b} *}$, Birgitta Gatersleben ${ }^{\mathrm{a}}$ and David Uzzell ${ }^{\mathrm{a}}$ \\ ${ }^{a}$ School of Psychology, University of Surrey, Guildford, Surrey GU2 7XH, UK; ${ }^{b}$ The Bartlett School of Construction \\ and Project Management, University College London, 1-19 Torrington Place, London WC1E 7HB, UK
}

\begin{abstract}
Despite the importance of demand response (DR), there has been little exploration of its potential impact on the individual or society. To address this gap, semi-structured interviews were conducted with 21 households in the south of England, in which two DR vignettes were presented: peak pricing and remote demand control during critical peaks. Peak pricing was seen as inequitable, burdening the less affluent, the less healthy, families and working mothers. Adverse societal outcomes may result from peak pricing, with potential for disruption of time-dependent household routines including the socially vital ritual of family mealtimes. Householders perceived their peak-time consumption to be determined by society's temporal patterns and not within their control to change. Third-party control in demand-side management was perceived to contravene householders' rights of control inside their homes. Alternative approaches to shifting peak demand, which combine technological, economic and socio-psychological insights, are considered.
\end{abstract}

Keywords: demand response; demand-side management; dynamic pricing; peak energy consumption; qualitative; inequity

\section{Introduction}

Demand response (DR) has been positioned as essential to energy policy in Europe (EU 2011). In response to the threat of global warming, which greenhouse gas emissions from human activities are exacerbating (IPCC 2013), policy-makers are seeking to reduce emissions through improved energy efficiency. Smart grids are seen as crucial facilitators of this objective, but it is DR which is expected to facilitate greatly increased levels of energy efficiency (Faruqui, Harris, and Hledik 2010). To date, there has been extensive research on the economic and engineering aspects of DR but little exploration of its potential impact on the individual or society. The current paper aims to address this gap.

Traditionally, energy systems were designed and planned from the perspective of energy generation (Bilton et al. 2008). However, seasonal variation and overcapacity to deal with peaks

\footnotetext{
*Corresponding author. Email: n.murtagh@ucl.ac.uk
} 


\section{N. Murtagh et al.}

mean that significant inefficiency has been designed into existing power systems. In the UK, total consumption can be under 55\% of capacity (Strbac 2008). In the smart grid, the electricity infrastructure will be augmented with a two-way digital communications network between enduse premises, distribution and transmission nodes and generating centres. The smart grid will reach end-user premises through smart meters. Already underway in several European countries, national rollout of smart meters in the UK is planned from 2015 to 2020, and an accompanying communications campaign emphasises that this will enable consumers to 'take control' (Smart Energy GB, 2014). With smart metering, there is the potential not only to predict demand to a much finer degree of granularity but also to influence demand. This capability is known as DR and is critical to realising the anticipated benefits of the smart grid (EU 2011).

Definitions in the literature of DR overlap with those of demand-side management and appear to reflect either an engineering or an economics approach. Definitions from the engineering perspective include 'the ability to control end-user devices (appliances) by rescheduling their operation' (Pina, Silva, and Ferrao 2012, 128), although it is far from clear how this fits with the UK communications campaign emphasising consumer control. From the economic perspective, DR is understood as price signalling in some form, such as time of use, real-time pricing or demand-side bidding (Bilton et al. 2008). A wider perspective potentially including either or both approaches has been recognised (Fitzgerald, Foley, and Mckeogh 2012; Torriti, Hassan, and Leach 2010). A critical factor missing from these definitions, however, is that of the consumer, the person who uses the energy and can choose to respond (or not) by changing his/her pattern of usage.

Congruent with the absence of the end-consumer in definitions of DR are the overly simplistic assumptions made about individual behaviour when consumers have been considered in studies and models. The prevailing assumptions are of decision-making driven by rational utility and of information deficit as a cause of failure to change behaviour (EU 2011; Meyers, Williams, and Matthews 2010; Strbac 2008; Torriti, Hassan, and Leach 2010). Rational utility assumes that consumers seek to optimise their (economic) benefit and hence behaviour is expected to correlate with financial incentives. Within this perspective, it follows that when consumers do not behave to maximise their utility, the problem is inadequate information: if only they had the right information, they would behave as expected. Indeed, 'just as consumers have learned to respond to the volatile prices of gasoline, fruits and vegetables, and other commodities, so they can learn to respond to electricity prices' (Spees and Lave 2007, 81).

However, the model of the rational utility in human decision-making has long been rejected. From the starting point that human cognition is not compatible with the systematic computation of utility (Simon 1955), cognitive and social psychologists have shown that decision-making (and thus behaviour) is influenced by - inter alia - biases, habit, identity, emotion and group norms, as well as information (Aarts, Verplanken, and Van Knippenberg 1998; Johnson-Laird and Oatley 2004; Kahneman, Slovic, and Tversky 1982; Murtagh, Gatersleben, and Uzzell 2012; Nolan et al. 2008). Furthermore, there is ample evidence that energy behaviour is not a matter of buying a commodity such as vegetables. Energy use in the home is a social behaviour and may be related to caring for others: for example, householders may decide when to wash clothes depending on when their children require clean school uniforms (Murtagh, Gatersleben, and Uzzell 2014). There are wide-ranging subjective differences between households in what constitutes necessary use of energy and what is therefore perceived as not possible to change (Hargreaves, Nye, and Burgess 2010, 2013). Energy behaviours may be symbolic, such as the use of lighting to create cosiness (Aune 2007). Energy practices such as showering and warmth are strongly 
culturally influenced (Shove 2003). There is a need therefore to examine the complexity of how people may respond to the technical and economic instantiations of DR.

Within existing research on changing energy behaviours, many studies have examined the effect of feedback and these have shown mixed results. It has been argued that a small number of highly motivated households may have contributed much of the positive outcomes found (Alexander 2010; Murtagh, Gatersleben, and Uzzell 2014), and meta-analyses have suggested that feedback alone is not sufficient to change behaviour (Abrahamse et al. 2007; EhrhardtMartinez, Donnelly, and Laitner 2010; Stromback, Dromacque, and Yassin 2011). Research within engineering domains has examined the characteristics of domestic appliances and their suitability for remote management (Baghina et al. 2012; Finn, O'Connell, and Fitzpatrick 2013; Fitzgerald, Foley, and McKeogh 2012). A number of these studies have recognised that some appliances, such as those for cooking, are not suitable for remote management because of the potentially adverse impact on customers (Pina, Silva, and Ferrao 2012; Soares, Gomes, and Antunes 2014). From economic disciplines, there has been work on improving models of domestic energy usage (Iwayemi et al. 2011; Richardson et al. 2010). Trials of dynamic pricing have been conducted with householders (see Darby and McKenna 2012; Faruqui and Sergici 2010 for reviews). Although conclusions have tended to be positive, we would suggest a more tentative view: as acknowledged by authors and reviewers, the number of observations in many trials was small; few studies supported their results with tests of statistical significance and in many studies, participation was voluntary and so the findings hold only for those end-users who were sufficiently interested and motivated to take part. Indeed, there is recent evidence that simply believing they are part of a study can, in itself, induce households to reduce energy consumption (Schwartz et al. 2013). More recent papers have begun to address the gap on the consumer's perspective. Darby and McKenna (2012) discussed social aspects of DR from a theoretical stance. Goulden et al. (2014) presented a compelling account of conceptualisations of electricity users as 'electricity consumers' and 'electricity citizens' in engaging with two possible configurations of a future smart grid. The current study seeks to contribute to the emerging body of research on changing energy behaviours in the home, by focusing on how householders describe their responses to two DR vignettes.

\section{Method}

The study adopted an exploratory qualitative design. A qualitative methodology offers a means of critical interpretation of action, thinking and experience (Denzin and Lincoln 2011), and our objective was to move beyond a simple analysis of outcomes of DR to examine contributing factors. By adopting a qualitative approach, we sought to gain richness and depth of understanding, to learn from the thinking and behaviour of consumers themselves. We sought to understand what matters to householders in DR and in the context of their lived experience that may have a bearing on their likelihood to change their patterns of energy usage. Qualitative research does not seek to test a priori theory though the analysis stage may draw on existing theory to elaborate or support findings, as we do here. We chose an established analytic method, thematic analysis (Braun and Clarke 2006), which permits not only the analysis of reasoning and understanding as described by the participants but also the critical analysis of latent themes by the researcher. Thus, it allows the analyst to move beyond surface readings of accounts and to look for patterns, differences and linkages to theory, to build deeper understanding of the phenomena in question.

The study was designed in combination with another study on in-home displays providing electricity feedback. As the latter study is published elsewhere (Murtagh, Gatersleben, and Uzzell 


\section{N. Murtagh et al.}

2014) and gives full details of data collection, the method is summarised here. Twenty-one households in the south of England were interviewed, in both suburban and rural settings. Recruitment was done through a community sustainability project (10 households), an eco-home development ( 3 households) and households not involved in sustainability initiatives ( 8 households). A small monetary incentive $(£ 15 / € 18$ or $£ 25 / € 30)$ was offered.

\section{Participants}

Three households were of Asian/British Asian ethnicity, one household was Black/Black British and the remainder were White/White British. Five households had an annual household income of above $£ 60,000$, and three had an annual income of less than $£ 10,000$ (median household income for England in 2011 was $£ 22,000 / € 26,000$ ). The households included sole occupants (2), couples without children at home (4), couples with children under 10 (5), couples with teenage children (6) and retired couples (4). Pseudonyms are used in the extracts below to protect anonymity.

\section{Procedure}

The interviews were conducted in 2012/2013 in the participants' homes with one or two family members. All participants were invited to include other family members, and the number of interviewees was the decision of the participants. Conducted by the lead author, each interview lasted about one hour and was audio-recorded for subsequent verbatim transcription.

The interviews were semi-structured. Two vignettes relating to DR (described further below) were introduced in turn: peak pricing and remote demand control for critical peaks. The vignettes were prefaced with a brief explanation of what is meant by peak usage, its impact on the energy system and the economic and environmental benefits of reducing peak demand. The vignettes were selected to represent both active (energy consumption altered by householder action Vignette 1) and passive (energy consumption altered by technology - Vignette 2) techniques from the taxonomy of DR defined by Bilton et al. (2008). Peak pricing (time of use) was selected for Vignette 1 as the simplest form of DR pricing, and easiest to explain to participants in an interview. Whereas Vignette 1 looked at shifting peak demand, Vignette 2 explored the acceptability of technological enablers. The choice of appliances in Vignette 2 could affect the responses of householders. We chose two technologies (freezer and immersion water heating) that have been explored in the literature because of the combination of contribution to household energy consumption, technical suitability for remote control and invisibility of such control to the consumer (Baghina et al. 2012; Fitzgerald, Foley, and McKeogh 2012).

\section{Findings}

\section{Peak pricing}

\section{Motivation}

A vignette of peak pricing was presented, in which the cost to the consumer of electricity in the peak period of 17:00-19:00 hours on weekdays was three times the cost of non-peak. More than half of participants (12 out of 21) indicated that they would respond to the price signals and reduce their electricity consumption in that period. Of the households who stated an intention to respond, over half (7 out of 12) were not in full-time, fixed daytime hours of employment: 
they were part-time or shift workers, self-employed or retired. Such households may have more flexibility in routines which would allow them to shift demand: "with the [work] shifts, I think that would work' [Jennifer]. For some of those who indicated an intention to change, it was seen as financially unavoidable: 'If it came about, we'd have to change our habits - that's all I could say, because we couldn't pay three times as much at that time, we just couldn't' [Gill, on pension support]. Several participants referred to the cost savings, but some mentioned motives beyond saving for changing their behaviour: if it was 'in the general good' [Ross] or 'if you're saving money and it's doing something that's productive' [Alan]. These householders appeared to respond to the notion of shifting peak use as a shared responsibility.

However, although some participants felt that they would try to shift demand in response to the peak pricing vignette, aspects of their current household energy use described elsewhere in the interview suggested that there could be limitations on the extent to which they would change. Other household members may not change. Existing routines may appear unchangeable: '[The washing machine is on] every single day. Because the amount of clothes that we generate, you know, I mean, all of us change clothes every day' [Amrit].

More generally, for participants who appeared not to respond to current prices, it seemed less likely that they would respond to peak pricing. For example, in one household:

I've got a big-ass TV ... I also use it as a radio ... And I got a computer inside the room. I got a server there. My son upstairs has got a computer that stays on all the time ... and he's also got a LCD and Xbox and everything-there-is box. [Luca]

But the same participant also said "[If I was asked] "Would you be interested in saving?" Course I would!' In this extract, we can see expressed attitudes that are not congruent with current behaviour, and unlikely to match future behaviour - an example of the 'value-action gap' (Kollmuss and Agyeman 2002). More generally, there was evidence of some of the factors that may moderate the translation of intention into behaviour, including social practices (Warde 2005) such as clothes washing, and household dynamics.

Between those who would feel financially compelled to reduce consumption in peak times and those who would not, there were other households who would be aware of higher costs but not motivated to change: for this household, their decision-making was clear:

... the kids need their uniform ... And we can't just sort of tell the kids, 'Oh, we're not going to do any washing until 8 o'clock this evening, but it's going to be a bit wet!' Because at the end of the day, well, how much are you going to save - you might save three or four pounds, but the inconvenience on a Monday morning when they haven't got five more shirts is probably a lot more hassle! [Nidal]

For this family, perception of external pressure (the uniform must be ready), responsibility to their children and 'hassle' were factors that even an acknowledged financial disincentive would not outweigh.

\section{Negative attitudes}

A number of householders perceived peak pricing in negative terms: as coercion 'I think that's the way to force people to change' [Ben] and others saw it as 'a deterrent' [Joe], a 'punishment' [Luca] and 'excessive' [Ruzwana]. For one participant, it appeared to infringe on personal freedom: 'And it's your home. So why would you want to wait till whatever time?' [Ruzwana], implying that she had the expectation and even the right to behave as she wished within her own 
home. In contrast to the householders who had perceived a shared responsibility in peak energy reduction, the conception of peak pricing as an instrument wielded by the utility companies against the consumer can be seen in the views of this householder:

But like my wife said, I think it is a bit of a liberty that they would take if they did do that. You know, because that's the peak time ... that's the main time that people are coming home, the kids are coming home, and everyone's coming home from work. And you're trying to say that you're trying to ration people from using things. I think the majority of people are going to do it whether they like it or not. [Amrit]

Where people believe they cannot change or are being forced to change, there may be resentment against higher prices when it is perceived that energy use is essential in those periods.

Beyond the issue of peak pricing as a financial disincentive, for some households, shifting their demand from peak time appeared impossible because their routines were subject to external societal temporal patterns:

I can't see that happening. I really can't. I mean, we couldn't have our meal in the middle of the day, for instance, because we're not here - we're both at work. So, we're always going to be eating at that time, aren't we? [Ben]

Several participants felt that, to introduce peak pricing, society at large would need to change. These responses also suggest that family meal times were important to the participants.

It was not only cooking and warmth that would pose problems. When considering delaying use of the washing machine until night-time, Colin, with two young children, noted 'if it switches on in the night, you already have three other loads waiting ... who changes [each load from washing machine to dryer]?' This illustrates that behaviour change may be necessary not only when an appliance is in use but also in the periods leading up to and after appliance use. Generally, it was families with children who mentioned clothes washing demands and the temporal nature of those demands.

\section{Inequity}

We noted above that some households felt that they would be financially obliged to change. In contrast, for other households, the financial incentive or penalty would be insufficient to engender change: 'We wouldn't change if our pockets didn't notice it' [Dave]. The inequitable burden was clear to participants:

It's very divisive. It comes down to whether you can afford it or not. It's not the same for everybody. Some people would have to do it because they can't afford not to, and others would have the luxury of being able to .... afford not to have to do that. [Susan]

Although the inequity of dynamic pricing has been noted by scholars (Darby, 2012; Faruqui 2010), it is of note that it was also clear to 'lay' householders, not only those who may have been in or close to fuel poverty.

Particular difficulties for some households in shifting demand were raised: 'People who have young kids are ... they're going to want to eat at five. They can't make them wait till eight because they'll be in bed by then' [Jack]. The issue of having a physiological need to eat at certain times extends to others, to the elderly, to people with illnesses such as diabetes and to those in poor health more generally. Two of the older participants mentioned the importance 
for their health of a regular cooked meal. A disincentive to eat a cooked meal when needed and convenient may have adverse impact on the health and well-being of already disadvantaged groups. Within the households interviewed, it appeared that attempting to deal with peak tariffing would cause particular difficulties for working mothers. Carrying the responsibility on behalf of the household for most domestic tasks, working mothers explained that many tasks had to be completed between coming home from work and going to bed, including cooking, washing up and washing clothes which could be needed for school the next day. This gave little or no scope to vary the time in which chores were completed.

Outside of the desired shifts in behaviour, there was evidence that householders could turn to alternative solutions. A pensioner of 77 said: 'I'd just use oil-lamps and candles.' The use of a solid fuel burner for cooking or heating water was mentioned by several households. Others would use gas, an oil Aga, microwave or consider constructing an outdoor wood burner. One participant thought he would try to construct battery backup to store electricity from the off-peak period. Clearly, some of these alternatives increase risk of fire or, if the home is not suitably constructed, suffocation.

\section{Remote demand control during critical peaks}

The second vignette addressed critical peaks, in which emergencies on the electrical grid would be handled by the electricity supplier turning off some home appliances for a short period (e.g. water immersion heating for up to 30 minutes; freezer for up to 15 minutes). Customers would opt into such a contract with slightly lower rates overall, a limited number of critical events per household per annum and a day's advance notification of supplier control of appliance.

Some participants (5 out of 21) were open to the idea, saying they could work around it. Once again, the motivation was not only financial:

If it was something we were doing which was because we needed to do it to stop power outages and ... if we didn't do it, it means you have power outages and people, vulnerable people, might suffer, I'd be ... willing to sign up to that. [Ross]

For these participants, there was a sense of civic responsibility and of moral duty. Thus there is potential, even without financial incentives, to engage some consumers in avoidance of demand at critical peaks. This adds to the evidence of the potential for critical peak reduction through information alone (Strengers 2010). Their responses also speak to the argument that critical peak pricing may signal new meanings about energy in critical peaks as valuable, scarce and fragile (Strengers 2013).

However, two overriding concerns emerged: almost half of households (9 out of 21) expressed concern about the loss of individual control; and almost half ( 9 out of 21, 5 participants expressed both concerns) were worried about the reliability of the technology and its implementation. In general, participants felt that they alone should have control over what happened in their home: 'I think the fact that they can just decide what things you have on in your own home is a bit too much' [Pete]. Several of the concerns expressed around technology related to whether an appliance would reliably return to service. This may have been a particular issue because the vignette suggested the freezer as a possible appliance for external control. For some people, the concern included both technology and the management of external control more generally: 'I don't think it would run smoothly, and stuff. I just - no, I don't like that one. There's too much margin for sort of cock-ups and errors and just things to go wrong' [Vickie]. 


\section{N. Murtagh et al.}

For some, there was a clear link to the lack of trust in the current supplier: 'I don't want British Gas getting involved in the minutes of my day' [Vickie]. This echoed the distrust of electricity utility companies voiced in discussions on peak pricing. For many, the profit motive of the privatised companies and their responsibility to shareholders rather than customers was a major issue: 'They're just out to maximise their profits and they don't really care' [Nadal]. Beyond assumptions of profit motives, participants felt that utilities were not to be trusted: 'It's all been sold off and they're all going to rip you off, essentially' [Vickie]. Some householders felt that the utility companies had 'hidden agendas', and that prices would be increased outside of peak times too. In summary, around half of the householders expressed deep distrust of electricity suppliers.

\section{Discussion}

In interviews in the south of England with 21 households of varying demographics, there were mixed responses to vignettes of peak pricing and of remote demand control in critical peaks. Although some households believed they would respond to peak pricing, it was generally viewed negatively and was seen as inequitable in its impact. The potential burden would impact in particular on those with limited financial means, those in poor health, families with children and working mothers. The temporal patterns of society were perceived to determine household routines during peak hours, and householders felt that changing such routines was therefore not within their control. The householders interviewed could respond to peak pricing by seeking alternative sources of energy. A number of participants voiced acceptance of third-party remote demand control during critical peaks, but the majority considered their own control of appliances in the home as a right. In addition, participants displayed a deep distrust of utility companies.

The anticipated shift of peak demand through peak pricing is predicated on the effectiveness of a financial incentive to change behaviour. The participants' responses indicated that a number would indeed intend to change behaviour. However, their reasons were mixed and not necessarily in line with freely chosen economic utility. Some households were clear that their behaviour would change because they had no alternative: due to their limited financial means, peak pricing would operate as coercion. The unequal burden evident in the participants' responses supported quantitative and theoretical arguments in the literature on the potential for inequity in DR (Darby 2012; Faruqui 2010) and additionally challenged the econometric view that lower spend on energy in fuel-poor households may indicate a benefit to these households (Darby 2012). Our evidence suggests that lower spend may be experienced as enforced and may be achieved through reducing energy consumption which has a direct bearing on well-being, such as reduced cooking or heating. There is a need for further evidence of the experience of DR in households that are fuel-poor, in poor health and otherwise disadvantaged. To consider only the outcomes of trials in economic or energy terms risks missing critical impacts on individuals, families and society.

The inequality of peak pricing was noted by participants other than those of restricted financial means. This was unexpected as the interview schedule focused on impact within the household and not on society more generally. If tariff regimes are widely perceived as coercive and unfair, breaching concepts of equality and social justice, there is risk of resentment and potentially of resistance, giving rise to the backlash described by Alexander (2010) which stopped a number of dynamic pricing programmes in the USA. For a few households in the current study, there were reasons beyond savings that could motivate change, with these participants perceiving a 
shared responsibility for reducing peak demand. This points to a sense of civic responsibility, of moral norms. Moral norms have been demonstrated to influence energy conservation in the home (Black, Stern, and Elworth 1985) and other energy-related behaviours (Eriksson, Garvill, and Nordlund 2006) and could be further explored as an alternative to financial incentives.

The widespread use of electricity for cooking meant that attempts to change energy use in peak times would affect the main meal of the day for many households. Participants were resistant to the idea of making such a change, arguing that the household main meal was determined by societal patterns of work and school hours, as well as by physiological needs. A change here, then, was perceived by some as beyond their control, conflicting with the communications campaign for smart meters in the UK. Some participants emphasised the importance of the family meal in their own household, and this is supported by robust evidence for family meal times as important occasions for society at large. Research has demonstrated the positive contribution of family meals not only to adolescent nutrition (Videon and Manning 2003), but also to literacy development in children (Snow and Beals 2006), to emotional well-being of children and creation of family identity (Fiese, Foley, and Spagnola 2006) and to improved academic achievement and decreased likelihood of early drug and alcohol abuse (Fiese, Hammons, and Grigsby-Toussaint 2012). The potential of peak pricing to compel families to change their eating patterns through financial mechanisms contravenes many policy goals for society, including those on obesity and health, support for the family unit, social mobility and education.

A theme through many accounts, particularly in the rural households, was that of pursuing alternative energy sources, from candles for lighting to cooking on solid fuel burners. There was evidence of potential for a rebound effect in the use of gas rather than electricity, potentially weakening the contribution to emissions' targets planned from reducing peak demand. An increase in the use of solid fuels would add to air pollution, already a major public health issue in the UK (Yim and Barrett 2012). When faced with a challenge, people can show ingenuity and initiative. Unplanned and unintended responses to peak pricing are possible.

In their responses to the remote demand control vignette, most households were unlikely to agree to third-party control of domestic appliances. Furthermore, their responses were linked to a lack of trust in utility companies, an issue noted in other studies (e.g. Goulden et al. 2014). Theoretical perspectives on trust have suggested three underlying dimensions: ability, benevolence and integrity (Ingenhoff and Sommer 2010; Mayer, Davis, and Schoorman 1995). Of interest here is that all three dimensions emerged in householders' responses. This speaks to ongoing findings of low levels of trust in the energy industry in many countries but particularly in the UK, at $35 \%$, the second lowest proportion of a general population sample who expressed trust in their utility company from 25 countries surveyed (Edelman 2014). The pervasiveness and depth of mistrust may pose a major challenge to any initiatives from existing energy companies in attempts to reduce or shift peak demand. The participants' responses in general aligned with the conceptualisation of Goulden et al. (2014) of the 'energy consumer', particularly in the sense of othering energy producers (e.g. 'they can just decide'). Goulden et al. (2014), Strengers (2011) and others argue for the possibility of alternative framings of energy production and consumption in which there is co-construction of practices of both demand and generation.

The responses here suggested that, alongside the lack of trust in suppliers, the issue of control over appliances in the home was an additional factor. There was evidence to suggest that control of one's own home in itself was a matter of importance to householders. Despite the potential for technical solutions to peak demand, householders viewed their homes as a private domain in which they themselves should have full control. Any third-party control would infringe the boundaries of ownership, control and individual rights. 
Although a qualitative study enables nuanced exploration of experiences and feelings, there were limitations to our approach. Firstly, the householder responses may be considered a selfreport, which may not reflect actual behaviour, as we noted above. Further, our vignettes required the participants to imagine future experience which poses methodological difficulties (Goulden et al. 2014). In responding, they may have drawn on different cognitive, affective and motivational processes than may be salient when actually experiencing the vignette events. A field trial may show quite different responses. However, field trials which are 'opt-in' can comprise a biased sample of participants, whereas a vignette approach can give voice to householders who would not voluntarily participate in a trial. Multiple approaches are necessary to understand the range of behaviours and experiences that DR may engender.

The preceding discussion of participant household responses to peak pricing and to remote demand control has considered a number of challenges to the implementation of both approaches to shifting peak demand. Nevertheless, the need to reduce peak electricity use remains a crucial component of achieving national targets for greenhouse gas reduction. How then can it be attained? Building from the responses of the participants are a number of possible ways to address the challenges. An offer of an optional 'shift workers' tariff which comprised preferential rates for low-usage periods could appeal to customers with flexible household schedules. An optional approach would avoid the issues caused by perceptions of coercion and inequity of universal peak pricing. An alternative approach is through technology. Using technology currently under development, it will become feasible to differentiate energy services within the home (Armel et al. 2013). Using software disaggregation techniques, the energy services that can have a major impact on quality of life and on important societal rituals such as the family meal, that is, cooking and heating, could be lifted out of peak tariffing. In this way, energy behaviours with potentially the greatest adverse social impact could be ring-fenced. Development of more sophisticated algorithms in tariffing could permit the segmentation of the consumer base and take out of demand pricing households that have elderly, disabled or very young members. Beyond economic and technical solutions, societal context is critical. Current approaches to DR position responsibility for change at the household level, yet the participants here described how household routines are embedded in those of wider society. More radical solutions encompassing societal temporal routines and practices are required. Policies coordinating work and school schedules have been trialled in parts of Germany and Italy (Reisch 2001). Such innovation could enable and perhaps drive changes to energy practices inside and outside the home.

In summary, the blunt instruments of peak pricing and of automated DR may meet resistance and may result in adverse societal outcomes. More sophisticated societal, technical and sociotechnical approaches are needed.

\section{Acknowledgements}

This work was supported by the Digital Economy Programme of the Research Councils UK under the REDUCE project grant (No. EP/1000232/1).

\section{Notes on contributors}

Niamh Murtagh is a Researcher at University College London. Her research centres on sustainable behaviour and behaviour change.

Birgitta Gatersleben is Senior Lecturer in Environmental Psychology at the University of Surrey. Her work focuses on understanding sustainable consumer and mobility behaviour, and human experiences with the natural world. 
David Uzzell is Professor of Environmental Psychology at the University of Surrey. He is particularly interested in sustainable behaviour in the workplace, and the role of heritage in the construction of national identity.

\section{References}

Aarts, H., B. Verplanken, and A. Van Knippenberg. 1998. "Predicting Behavior from Actions in the Past: Repeated Decision Making or a Matter of Habit?” Journal of Applied Social Psychology 28 (15): 1355-1374.

Abrahamse, W., L. Steg, C. Vlek, and T. Rothengatter. 2007. "The Effect of Tailored Information, Goal Setting, and Tailored Feedback on Household Energy Use, Energy-related Behaviors, and Behavioral Antecedents." Journal of Environmental Psychology 27 (4): 265-276.

Alexander, B. R. 2010. "Dynamic Pricing? Not so Fast! A Residential Consumer Perspective.” The Electricity Journal 23 (6): 39-49.

Armel, K. C., A. Gupta, G. Shrimali, and A. Albert. 2013. "Is Disaggregation the Holy Grail of Energy Efficiency? The Case of Electricity." Energy Policy 52: 213-234.

Aune, M. 2007. "Energy Comes Home.” Energy Policy 35 (11): 5457-5465.

Baghina, N., I. Lampropoulos, B. Asare-Bediako, W. L. Kling, and P. F. Ribeiro. 2012. "Predictive Control of a Domestic Freezer for Real-time Demand Response Applications." In 3rd IEEE PES Innovative Smart Grid Technologies, 1-8. Berlin: IEEE .

Bilton, M., C. Ramsay, M. Leach, H. Devine-Wright, P. Devine-Wright, and D. Kirschen. 2008. "Domestic Electricity Consumption and Demand-side Participation: Opportunities and Challenges for the UK Power System." In Delivering a Low-carbon Electricity System: Technologies, Economics and Policy, edited by M. Grubb, T. Jamasb, and Mg. Pollitt, 207-228. Cambridge: Cambridge University Press.

Black, J. S., P. C. Stern, and J. T. Elworth. 1985. "Personal and Contextual Influences on Household Energy Adaptations." Journal of Applied Psychology 70 (1): 3-21.

Braun, V., and V. Clarke. 2006. "Using Thematic Analysis in Psychology." Qualitative Research in Psychology 3 (2): 77-101.

Darby, S. J. 2012. "Metering: EU Policy and Implications for Fuel Poor Households." Energy Policy 49: 98-106. http://www.sciencedirect.com/science/article/pii/S0301421511009633.

Darby, S. J., and E. Mckenna. 2012. "Social Implications of Residential Demand Response in Cool Temperate Climates." Energy Policy 49: 759-769.

Denzin, N. K., and Y. S. Lincoln. 2011. "Introduction: The Discipline and Practice of Qualitative Research." In The Sage Handbook of Qualitative Research, edited by Nk. Denzin, and Ys. Lincoln, 1-20. Thousand Oaks, CA: SAGE.

Edelman. 2014. "2014 Edelman Trust Barometer Global Results.” Accessed May 5, 2014. http://www.edelman.com/ insights/intellectual-property/2014-edelman-trust-barometer/about-trust/global-results/ .

Ehrhardt-Martinez, K., K. A. Donnelly, and J. A. Laitner. 2010. Advanced Metering Initiatives and Residential Feedback Programs: A Meta-review for Household Electricity Saving Opportunities. Washington, DC: American Council for an Energy-efficient Economy.

Eriksson, L., J. Garvill, and A. Nordlund. 2006. "Acceptability of Travel Demand Management Measures: The Importance of Problem Awareness, Personal Norm, Freedom, and Fairness." Journal of Environmental Psychology 26: 15-26.

EU. 2011. Smart Grids: From Innovation to Deployment. Brussels: EU.

Faruqui, A. 2010. "The Ethics of Dynamic Pricing." The Electricity Journal 23 (6): 13-27.

Faruqui, A., D. Harris, and R. Hledik. 2010. "Unlocking the $€ 53$ Billion Savings from Smart Meters in the EU: How Increasing the Adoption of Dynamic Tariffs Could Make or Break the EU's Smart Grid Investment." Energy Policy 38: 6222-6231.

Faruqui, A., and S. Sergici. 2010. "Household Response to Dynamic Pricing of Electricity: A Survey of 15 Experiments." Journal of Regulatory Economics 38 (1): 193-225.

Fiese, B. H., K. P. Foley, and M. Spagnola. 2006. "Routine and Ritual Elements in Family Mealtimes: Contexts for Children's Wellbeing and Family Identity.” New Directions for Child and Adolescent Development 2006 (111): 67-89.

Fiese, B. H., A. Hammons, and D. Grigsby-Toussaint. 2012. "Family Mealtimes: A Contextual Approach to Understanding Childhood Obesity." Economics and Human Biology 10 (4): 365-374.

Finn, P., M. O'Connell, and C. Fitzpatrick. 2013. "Demand Side Management of a Domestic Dishwasher: Wind Energy Gains, Financial Savings and Peak-time Load Reduction.” Applied Energy 101: 678-685. http://www.sciencedirect.com/science/article/pii/S0306261912005156. 
Fitzgerald, N., A. M. Foley, and E. McKeogh. 2012. "Integrating Wind Power Using Intelligent Electric Water Heating." Energy 48 (1): 135-143.

Goulden, M., B. Bedwell, S. Rennick-Egglestone, T. Rodden, and A. Spence. 2014. "Smart Grids, Smart Users? The Role of the User in Demand Side Management.” Energy Research and Social Science 2: 21-29. http://www.sciencedirect. com/science/article/pii/S2214629614000413.

Hargreaves, T., M. Nye, and J. Burgess. 2010. "Making Energy Visible: A Qualitative Field Study of How Householders Interact with Feedback from Smart Energy Monitors.” Energy Policy 38 (10): 6111-6119.

Hargreaves, T., M. Nye, and J. Burgess. 2013. "Keeping Energy Visible? Exploring How Householders Interact with Feedback from Smart Energy Monitors in the Longer Term.” Energy Policy 52: 126-134. http://www. sciencedirect.com/science/article/pii/S0301421512002327.

Ingenhoff, D., and K. Sommer. 2010. "Trust in Companies and in CEOs: A Comparative Study of the Main Influences." Journal of Business Ethics 95 (3): 339-355.

IPCC. 2013. The Physical Science Basis. Climate Change 2013: Summary for Policymakers. Bern: Intergovernmental Panel on Climate Change.

Iwayemi, A., P. Z. Yi, X. H. Dong, and C. Zhou. 2011. "Knowing When to Act: An Optimal Stopping Method for Smart Grid Demand Response.” IEEE Network 25 (5): 44-49.

Johnson-Laird, P. N., and K. Oatley. 2004. "Cognitive and Social Construction in Emotions." In Handbook of Emotions, edited by M. Lewis, and J. M. Haviland-Jones, 458-475. New York: Guilford Press.

Kahneman, D., P. Slovic, and A. Tversky. 1982. Judgement under Uncertainty: Heuristics and Biases. Cambridge: Cambridge University Press.

Kollmuss, A., and J. Agyeman. 2002. "Mind the Gap: Why People Act Environmentally and What are the Barriers to Pro-Environmental Behavior?" Environmental Education Research 8 (3): 239-260.

Mayer, R. C., J. H. Davis, and F. D. Schoorman. 1995. “An Integrative Model of Organizational Trust.” Academy of Management Review 20 (3): 709-734.

Meyers, R. J., E. D. Williams, and H. S. Matthews. 2010. "Scoping the Potential of Monitoring and Control Technologies to Reduce Energy Use in Homes." Energy and Buildings 42 (5): 563-569.

Murtagh, N., B. Gatersleben, and D. Uzzell. 2012. "Multiple Identities and Travel Mode Choice for Regular Journeys." Transportation Research Part F 15 (5): 514-524.

Murtagh, N., B. Gatersleben, and D. Uzzell. 2014. “20: 60: 20 - Differences in Energy Behaviour and Conservation between and within Households with Electricity Monitors." PLoS ONE 9 (3): 1-12 . doi:10.1371/ journal.Pone.0092019.

Nolan, J. M., P. W. Schultz, R. B. Cialdini, N. J. Goldstein, and V. Griskevicius. 2008. "Normative Social Influence is Underdetected." Personality and Social Psychology Bulletin 34 (7): 913-923.

Pina, A., C. Silva, and P. Ferrao. 2012. "The Impact of Demand Side Management Strategies in the Penetration of Renewable Electricity." Energy 41: 128-137.

Reisch, L. A. 2001. "Time and Wealth: The Role of Time and Temporalities for Sustainable Patterns of Consumption." Time \& Society 10 (2/3): 367-385.

Richardson, I., M. Thomson, D. Infield, and C. Clifford. 2010. "Domestic Electricity Use: A High-resolution Energy Demand Model." Energy and Buildings 42 (10): 1878-1887.

Schwartz, D., B. Fischhoff, T. Krishnamurti, and F. Sowell. 2013. "The Hawthorne Effect and Energy Awareness." Proceedings of the National Academy of Sciences 110 (38): 15242-15246.

Shove, E. 2003. Comfort, Cleanliness and Convenience. Oxford: Berg Publishers.

Simon, H. A. 1955. “A Behavioral Model of Rational Choice.” Quarterly Journal of Economics 69 (1): 99-118.

Smart, G. B. 2014. "Take Control of Your Energy: The Smart Meter Rollout.” http://www.smartenergygb.org/ .

Snow, C. E., and D. E. Beals. 2006. "Mealtime Talk That Supports Literacy Development." New Directions for Child and Adolescent Development 2006 (111): 51-66.

Soares, A., A. Gomes, and C. H. Antunes. 2014. "Categorization of Residential Electricity Consumption as a Basis for the Assessment of the Impacts of Demand Response Actions." Renewable and Sustainable Energy Reviews 30 : 490-503.

Spees, K., and L. Lave. 2007. "Demand Response and Electricity Market Efficiency." Electricity Journal 20 (3): 69-85.

Strbac, G. 2008. "Demand Side Management: Benefits and Challenges.” Energy Policy 36: 4419-4426.

Strengers, Y. 2010. “Air-conditioning Australian Households: A Trial of Dynamic Peak Pricing.” Energy Policy 38 (11): $7312-7322$.

Strengers, Y. 2011. "Beyond Demand Management: Co-managing Energy and Water Practices with Australian Households." Policy Studies 32 (1): 35-58. 
Strengers, Y. 2013. Smart Energy Technologies in Everyday Life: Smart Utopia? Basingstoke: Palgrave Macmillan. Stromback, J., C. Dromacque, and M. H. Yassin. 2011. The Potential of Smart Meter Enabled Programs to Increase Energy and Systems Efficiency: A Mass Pilot Comparison. Brussels: VaasaETT/ESMIG.

Torriti, J., M. G. Hassan, and M. Leach. 2010. "Demand Response Experience in Europe: Policies, Programmes and Implementation.” Energy 35: 1575-1583.

Videon, T. M., and C. K. Manning. 2003. "Influences on Adolescent Eating Patterns: The Importance of Family Means." Journal of Adolescent Health 32 (5): 365-373.

Warde, A. 2005. "Consumption and Theories of Practice." Journal of Consumer Culture 5 (2): 131-153.

Yim, S. H. L., and S. R. H. Barrett. 2012. "Public Health Impact of Combustion Emissions in the UK." Environmental Science and Technology 46 (8): 4291-4296. 